\title{
El Niño monitoring system in failure mode
}

\section{US budget woes cripple a key mooring array in the tropical Pacific Ocean.}

\section{Jeff Tollefson}

23 January 2014

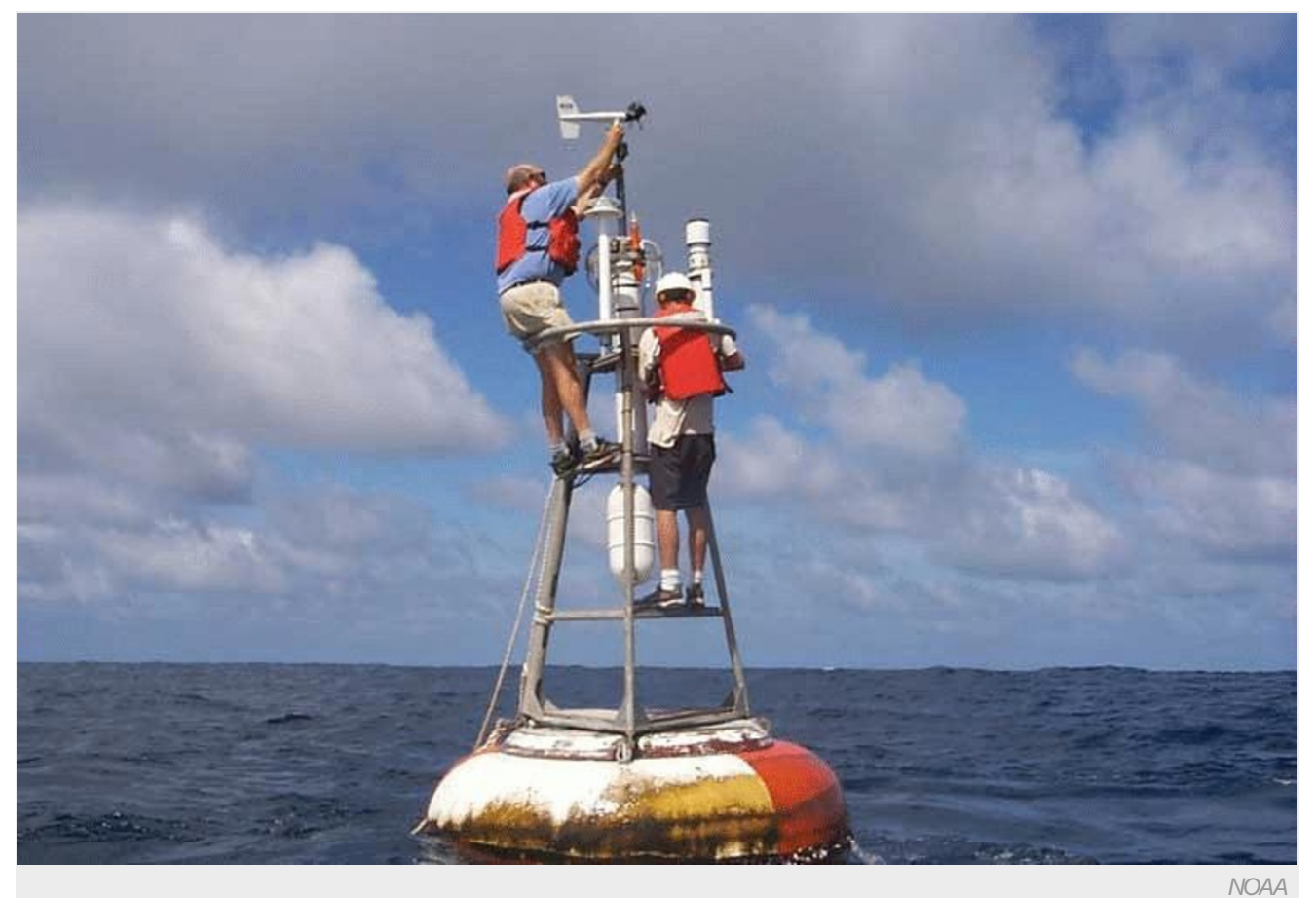

Nearly half of the buoys in the Tropical Atmosphere Ocean array have failed because of delayed maintenance.

An ocean-monitoring system that extends across the tropical Pacific is collapsing, depriving scientists of data on a region that influences global weather and climate trends.

Nearly half of the moored buoys in the Tropical Atmosphere Ocean (TAO) array have failed in the past two years, crippling an earlywarning system for the warming and cooling events in the eastern equatorial Pacific, known respectively as El Niño and La Niña. Scientists are now collecting data from just $40 \%$ of the array.

"It's the most important climate phenomenon on the planet, and we have blinded ourselves to it by not maintaining this array," says Michael McPhaden, a senior scientist at the US National Oceanic and Atmospheric Administration (NOAA) in Seattle, Washington. McPhaden headed the TAO project before it was transferred out of NOAA's research arm and into the agency's National Weather Service in 2005.

The network was developed over the course of a decade following the massive El Niño of 1982-83. NOAA maintains some 55 buoys across the eastern and central Pacific that monitor weather conditions as well as water temperatures down to 500 metres. Working in concert, the Japan Agency for Marine-Earth Science and Technology (JAMSTEC) maintains another dozen buoys in the western tropical Pacific. Combined, the monitoring system has become a cornerstone for seasonal weather forecasting given the tropical Pacific's influence on broader weather patterns.

\section{An array adrift}

The array's troubles began in 2012, when budget cuts pushed NOAA to retire a ship dedicated to performing the annual servicing that keeps the TAO buoys in working order. According to McPhaden, NOAA's annual budget for the project stood at about US\$10 million to $\$ 12$ million before 2012 - a figure that included around \$6 million to cover the dedicated ship. In fiscal year 2013, the agency spent $\$ 2$ million to $\$ 3$ million to charter boats for maintenance runs, but McPhaden says that these operations have not been enough to keep the system going. Meanwhile, although JAMSTEC has thus far kept its portion of the array up and running, it too is under budgetary 


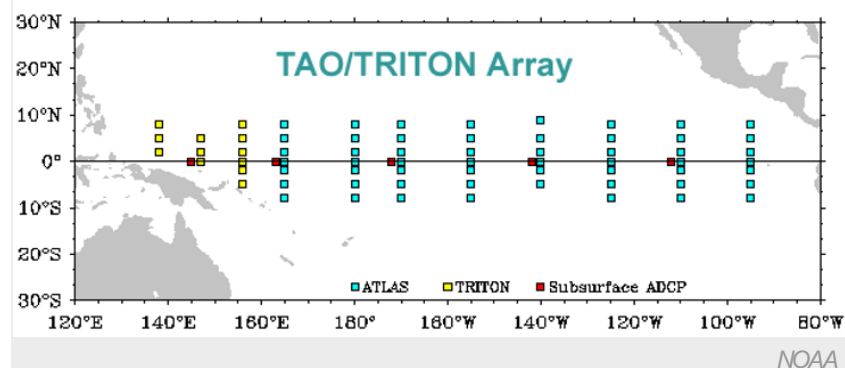

The TAO array monitors conditions in the tropical Pacific Ocean. Turquoise dots represent US buoys, while yellow dots show Japanese buoys.

"The array really revolutionized our science, and to let it deteriorate is such a waste of the investment the Americans have made over the past 30 years," says Wenju Cai, a climate modeller at the Commonwealth Scientific and Industrial Research Organization in Aspendale, Australia. Cai was the lead author on a recent paper ${ }^{1}$ with McPhaden and others projecting that global warming could double the frequency of extreme El Niño events - such as those in 1982-83 and 1997-98, each of which caused epic damage around the globe.
A cadre of researchers from around the world will meet next week at the Scripps Institution of Oceanography in La Jolla, California, to discuss possible solutions. NOAA has indicated that the agency will put additional resources into the programme this coming year, but few expect that this will be enough to fully restore the array.
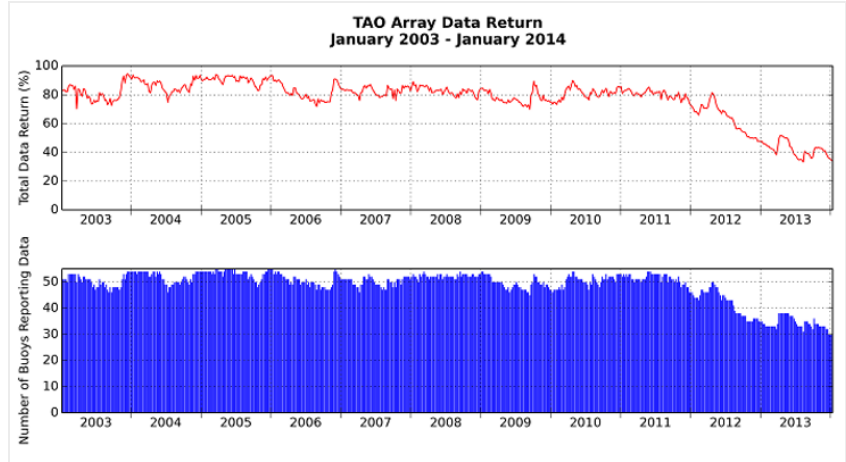

NOAA

The amount of data returned by the TAO array has plummeted as buoys have gone offline.

Buoys are not the only instruments monitoring the equatorial Pacific. Scientists also supplement data from the TAO array with measurements of both sea surface temperature collected via satellite and ocean temperature collected by the global network of freefloating buoys known as Argo, which dive and report data every ten days. But satellites cannot see beneath the ocean surface, and Argo floats cannot provide the kind of real-time measurements at specific locations that come from the array of moored buoys.

In addition to supporting climate research, the TAO array also provides basic data for seasonal weather forecasts issued by various government agencies around the world. The impact of the data loss on current predictions remains unclear, in part because the tropical Pacific has been in a neutral state since the buoy system began to fail. But there are signs that seasonal climate models are beginning to suffer from the lack of data, McPhaden says, and it would be a shame if another major El Niño were to arrive while the system is crippled.

"In my opinion, NOAA dropped the ball on an incredible programme for climate research and weather forecasting," McPhaden says. "And now they are trying to put Humpty Dumpty back together again."

Nature | doi:10.1038/nature.2014.14582

\section{References}

1. Cai, W. et al. Nature Clim. Change http://dx.doi.org/10.1038/NCLIMATE2100 (2014). 